\title{
The Relationship Among Spirituality, Fear, and Mental Health on COVID-19 Among Adults: An Exploratory Research
}

\begin{abstract}
Balan Rathakrishnan ${ }^{* \dagger}$, Soon Singh Bikar Singh ${ }^{1 \dagger}$, Azizi Yahaya1, Mohammad Rahim Kamaluddin ${ }^{2}$ and Siti Fardaniah Abdul Aziz ${ }^{2}$
\end{abstract}

${ }^{1}$ Faculty of Psychology and Education, University Malaysia Sabah (UMS), Kota Kinabalu, Malaysia, ${ }^{2}$ Centre for Research in Psychology and Human Well-Being, Faculty of Social Sciences and Humanities, National University of Malaysia, Bangi, Malaysia

OPEN ACCESS

Edited by:

Marcelo Saad,

Albert Einstein Israelite Hospital, Brazil

Reviewed by:

Azlina Md. Yassin,

Universiti Tun Hussein Onn Malaysia,

Malaysia

Jesús Saiz,

Complutense University of Madrid,

Spain

Hamid Sharif Nia

Mazandaran University of Medical

Sciences, Iran

${ }^{*}$ Correspondence:

Balan Rathakrishnan

rbhalan@ums.edu.my

†These authors have contributed equally to this work

Specialty section: This article was submitted to

Health Psychology, a section of the journal

Frontiers in Psychology

Received: 15 November 2021 Accepted: 06 December 2021

Published: 12 January 2022

Citation:

Rathakrishnan B, Singh SSB,

Yahaya A, Kamaluddin MR and

Aziz SFA (2022) The Relationship Among Spirituality, Fear, and Mental Health on COVID-19 Among Adults:

An Exploratory Research.

Front. Psychol. 12:815332.

doi: 10.3389/fpsyg.2021.815332
The novel coronavirus disease (COVID-19) is impactful on all aspects of individuals' lives, particularly mental health due to the fear and spirituality associated with the pandemic. Thus, purpose of this study was to identify the relationship among fear, spirituality, and mental health on COVID-19 among adults in Malaysia. This study also examines spirituality as a mediator in relationship between fear and mental health. The study involved around 280 adults in Malaysia. This research is a quantitative study. Data analysis method (SEM-PLS) has been used for data analysis. Based on descriptive analysis, mental health questionnaire indicated that $60.0 \%$ of them are at a poor level of mental health whereas $57.5 \%$ of respondents showed a moderate level of COVID19 fear, and $60.4 \%$ of respondents owned moderate level of spiritual well-being. The results also demonstrated that respondents that have a high level of fear would have a high level of mental health; interestingly, those with a high level of spirituality will have a lower level of mental health. Findings indicated that spirituality significantly mediated the relationship between fear and mental health. This research will help to demonstrate how important spirituality values to control mental health to be more positive among adults in Malaysia. The main contributions of this study are to help come out with new intervention method for those who are mentally ill and need help.

Keywords: spirituality, fear, mental health, COVID-19, adults

\section{INTRODUCTION}

In early 2020, coronavirus disease (COVID-19), originating from Wuhan in Hubei province, began to spread throughout China (Li et al., 2020). World Health Organization (WHO) stated that there is a high risk of COVID-19 spreading to other countries worldwide. In March 2020, WHO assessed that COVID-19 could be characterized as a pandemic (WHO, 2020). As a result, the majority of countries in the world have to take drastic measures to adopt a nationwide lockdown and practice social distancing to fight against and to flatten the curve of the COVID-19 infection. The spread of the disease without any vaccine and uncertainty and low expectations of COVID-19 not only threaten people's physical health but also poses challenges to people's mental health for the entire human race. For instance, in Italy, local people have high levels of stress due to no firm estimate 
of how long the pandemic will last and how long our lives will be disrupted or whether or not our loved ones or we will be infected (Montemurro, 2020).

In China, fear of abandonment, neglected death toll increase among patients, and feelings of loneliness and anger have developed among people who are quarantined (Xiang et al., 2020). Research by Zhang et al., 2020 shows that being quarantined decreases face-to-face connection and social interaction, and it contributes to the stressful situation among people. Besides, in India, most of the people are in fear, disgust, stress, and extreme sadness about the lockdown on March 25, 2020 (Barkur and Vibha, 2020), sleep difficulties, and paranoia about acquiring COVID-19 infection (Roy et al., 2020). One of the reasons is social isolation which can cause people to get stress (Holt-Lunstad et al., 2015).

Even though many coping techniques and procedures have been formulated for COVID-19, past studies have proved that spirituality values improve people's well-being. Richards and Bergin (2005) and Young et al. (2007) have demonstrated the connection between spirituality with mental health and wellbeing. Spirituality has helped people with making decisions and helping people to cope with stress when they have difficulty in life (Pargament et al., 1988; Thurston, 1999). When people are practicing spirituality values, they can overcome depression (Westgate, 1996; Srinivasan et al., 2003) and anxiety (Graham et al., 2001). Brown et al. (2013) in his research have proven that spirituality well-being has a significant effect on anxiety and depression and those who have a higher level of spirituality have a reduction in their mental illness. Furthermore, some research studies have been performed to investigate how spirituality could help people to improve their self-esteem, giving them moral support and searching meanings of life among patients with cancer (Thune-Boyle et al., 2006).

Another critical element that needs to be looked into is the fear of illness. Fear is related to the contemporary mental health system (Laurance, 2003). Fear is defined as the unpleasant emotional state that is elicited by a perceived threat (de Hoog et al., 2008). Due to the lack of control on the pandemic in terms of unavailability of an effective vaccine and treatment cure, individuals naturally began experiencing fear regarding developing the disease. Literature suggests that whereas fear of COVID-19 propels individuals to observe the rules that will help to minimizing the spread of the virus, it may also result in an array of psychological effect such as anxiety (Roy et al., 2020) and depression (Holmes et al., 2020). Fear is also linked with mental illness with different types of sociocultural factors such as our belief and dominant culture (Halliwell, 2009). Previous studies have highlighted that there is a significant relationship between the fear of illness and mental health (Laurance, 2003). Even though fear and mentality are positively related, but there is very few research that explores the relationship among fear of COVID-19, the value of spirituality, and mental health among adults in Malaysia. These three aspects are closely related, but how can they be seen during the COVID-19 pandemic. Even though spirituality and fear have been discussed in the past, there is still the question of how spirituality could help people who have mental illness and fear of disease. Research is still lacking regarding the pandemic, notably the COVID-19 pandemic.
The main aim of this study was to examine the relationship between fear of COVID-19 and mental health with an adult sample as mediated by spirituality. The hypotheses of the study included that (a) there is significant relationship between fear and spirituality, (b) there is significant relationship between spirituality and mental health, (c) there is significant relationship between fear and mental health, and (d) spirituality mediates the relationship between fear and mental health. As no studies per see examined such link between the concepts, exploring such relationship is certainly worth studying.

\section{LITERATURE REVIEW}

\section{Relationship Among Fear, Spirituality, and Mental Health}

According to behavioral explanations, spirituality and health are much related because of people behaviors, motivation, belief, attitudes, and thoughts. Physical and mental health are related to psychosocial variables, such as stress, lifestyle behaviors, and health-related cognitions. This helps us to understand how the practice of faith and spiritual path may import impact on psychological health. Individual prayers or worship may produce solution for emotions such gratitude, humility, forgiveness, and some of them be fear of doing bad things. As conclusion, the connections among mental health, spirituality, and fear are described (Levin, 2009).

\section{Relationship Between Fear and Spirituality}

Previous research has proved that those who have a fear of diseases but have spirituality values have positive mental health (Hayman et al., 2007; Koenig, 2010). Study by Fardin (2020) indicated that spiritualty aids people to have mental relaxation in times of crisis. Some of the religious solutions proposed against the COVID-19 prevalence could be helpful. This shows that spirituality values can help people who have a fear of coping with difficult situations. Thus, this research proposes the hypothesis below:

H1: There is significant relationship between fear and Spirituality.

\section{Relationship Between Spirituality and Mental Health}

Spirituality is unique in its definition because there is no precise definition of spirituality. Spirituality is looking for meaning in life, peace, bliss, understanding, faith, and love. Rosmiran (2020) mentioned that she has been talking and advising her patients to always have faith and hope to overcome their mental issue, especially during the COVID-19 pandemic. Even patients have been anxious about their life in this pandemic but hope and faith could help them to overcome their mental health state more positively. This proves how much spirituality values could boost up more positive mental health. Many past researches have discussed the relationship between spirituality and mental health (Seybold and Hill, 2001; Miller and Thoresen, 2003; Powell et al., 2003). Thus, this research proposes the hypothesis below: 
$\mathrm{H} 2$ : There is significant relationship between spirituality and mental health.

\section{Relationship Between Fear and Mental Health}

The fear of COVID-19 is undoubtedly affecting mental health condition of people. Research by Zhang et al., 2020 shows that during quarantine, people lose face-to-face connection and social interaction, and it contributes to a stressful situation among people. Fear can cause many mental health issues because people get worries related to disease and also because they have been isolated at home for a more extended period. People who already have some mental health issues will be more exceptional in having mental health risks such as fear and anxiety. This statement has been proven by Druss (2020). Fear is not only related to disease but also toward social distancing, and this has been proven by Holt-Lunstad et al. (2015), whereby social distancing can cause many health problems such as fear, guilt, unhappiness, and depression. His finding shows how much fear can contribute to mental health, and it becomes worse for those who already have some mental health issues. In China, fear of abandonment, being neglected and rising death among patients, and feelings of loneliness and anger have developed among people who are quarantined (Xiang et al., 2020). When social distancing was practiced in Malaysia, many adults feel that they are alone and are influenced by the many social media information. Thus, this research proposes the hypothesis below:

H3: There is significant relationship between fear and mental health.

\section{Spirituality as a Mediator}

Based on previous study, spirituality is the important variable as a mediator (Reutter and Bigatti, 2014; Trigwell et al., 2014). Spirituality values can help people to cope with fear and mental health issue. When spirituality values are high, people give less importance to emotion and become more focused on daily work. Even if people are experiencing social distancing and also having less social connectedness with their friends, family members, and colleagues, with spiritually, they can have faith and hope. This spirituality reduces their fear of disease. Spirituality makes them stronger in their relationship with fear and mental health (Bonelli et al., 2012). Furthermore, in Malaysia, adults are multiethnic whereby each of them has different faith and belief systems in society (Rathakrishnan et al., 2021). In light of these results, it is possible to conclude that spirituality assists individuals to cope better with life disruptions and allows them to view life more positively. Thus, this research proposes the hypothesis below:

H4: Spirituality mediates the relationship between fear and mental health.

\section{THE RESEARCH FRAMEWORK}

Figure 1 indicates the research constructs and the operationalization of the constructs based on the past studies.
Figure 1 shows the research framework of the study on how the fear impacts on spirituality with mental health, and spirituality becomes a mediator in relationship between fear and mental health. This is very crucial which concerns the spirituality of awareness and understanding of what issue the adults experiencing in their mental state and how it is related to fear also become an important element to consider necessary during the COVID-19 pandemic. Stemmed from the above framework, this research, therefore, derived a few hypotheses that are constructed as follows:

H1: There is significant relationship between fear and spirituality.

$\mathrm{H} 2$ : There is significant relationship between spirituality and mental health.

H3: There is significant relationship between fear and mental health.

H4: Spirituality mediates the relationship between fear and mental health.

\section{RESEARCH METHODOLOGY}

\section{Research Design}

This study has used convenient sampling design, and the total of 280 questionnaires was received from the respondents. Random sampling is the purest form of probability sampling. Each member of the population has an equal chance of being selected. This simple random sampling design has the least bias and offers the most generalizability (Sekaran and Bougie, 2013).

\section{Sample}

In this study, the population is the adults in Malaysia. Adults are classified as individuals who are above the age of 18 years. In 2019, there were approximately 21.82 million adults in Malaysia. According to Raosoft calculator the with the $90 \%$ and 0.05 is 271 sample size.

\section{Instruments and Measures}

Spiritual well-being questionnaire (SWBQ) was a set of selfrating questionnaires designed to measure personal's wellbeing, communal well-being, environmental well-being, and transcendental well-being (Gomez and Fisher, 2003). It consisted of a total of 20 items, containing five items for each domain

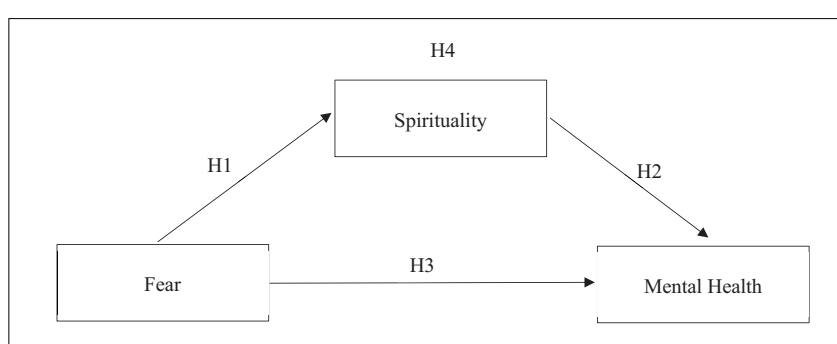

FIGURE 1 | Research framework. Obtained from Universiti Malaysia Sabah. 
mentioned previously. It used a four-point Likert scale ( 1 = very low, 2 = low, 3 = high, and 4 = very high).

Fear of COVID-19 Scale (FCV-19S) was seven items scale for measuring fear of COVID-19 (Ahorsu et al., 2020). The response type was modified from a five-point Likert scale to a four-point Likert scale ( 1 = strongly disagree, 2 = disagree, 3 = agree, and 4 = strongly agree).

Patient Health Questionnaire for Depression and Anxiety (PHQ-4) was used to measure respondents' mental health in terms of depression and anxiety (Kroenke et al., 2009). It consists of four items where two items are taken from Generalized Anxiety Disorder-7 (GAD-7) and another two from the Patient Health Questionnaire-8 (PHQ-8). It uses a five-point Likert scale $(0=$ not often at all, $1=$ not so often, $2=$ somewhat often, $3=$ very often, and 4 = extremely often). The greater the score in PHQ4 , the greater the level of depression and anxiety, and hence the lower the level of mental health. For this research, all measures for SWBQ, FCV-19, and PHQ-4 have been used 3 scales (low, moderate, and high) as suggested by Mohd Majid (2002).

\section{Procedure}

In this study, the respondents were recruited using a convenience sampling technique. The entire study was obtained ethical approval board reference to JKEtika 3/20 (11) from the Ethical Board of University Malaysia Sabah. Prior to data collection, signed consent was obtained from each respondent, and they were assured with anonymity and confidentially of data. A total of 280 respondents were selected for the purpose of this research.

\section{Data Analysis}

Data analysis method (SEM-PLS) has been used for data analysis.

\section{RESULTS AND DISCUSSION}

Table 1 shows that about one-third (36.1\%) of the respondents were men and the other $63.9 \%$ were women. In this survey, 198 (70.7\%) of the respondents are aged from 18 to 35 years old and $82(29.3 \%)$ aged from 36 to 56 years old with the mean age of 29.5. Most respondents (68.2\%) were single, $31.4 \%$ married, and $0.4 \%$ divorced. Totally, $171(61.1 \%)$ of the respondents were undergraduate, 66 (23.6\%) were graduate, and 43 (15.4\%) were postgraduate. In addition, $204(72.9 \%)$ respondents stayed in urban areas, whereas $76(27.1 \%)$ in rural areas.

Based on descriptive analysis as shown in Table 2, most respondents (41.4\%) self-reported a good level of mental health, whereas the mental health questionnaire indicated that $60.0 \%$ of them are at a good level of mental health. Overall, 96.4\% of respondents showed a moderate level of COVID-19 fear, and $60.4 \%$ of respondents owned a moderate level of spiritual well-being. About half of the respondents (50.7\%) indicated a moderate level of spiritual transcendence.

\section{Data Analysis Approaches}

In this study herein, the structural equation model used partial least squares regression (PLS regression) path model to verify
TABLE 1 | Distribution of respondents.

\begin{tabular}{lcc}
\hline & Frequency & Percentage (\%) \\
\hline Gender & 101 & 36.1 \\
Male & 179 & 63.9 \\
Female & & \\
Age group & 198 & 70.7 \\
18-35 years & 82 & 29.3 \\
36-56 years & 191 & \\
Marital status & 88 & 68.2 \\
Single & 1 & 31.4 \\
Married & & 0.4 \\
Divorced & 171 & \\
Education & 66 & 61.1 \\
Undergraduate & 43 & 23.6 \\
Graduate & & 15.4 \\
Postgraduate & 204 & 72.9 \\
Location & 76 & 27.1 \\
Urban & & \\
Rural & &
\end{tabular}

TABLE 2 | Descriptive analysis on mental health, fear of COVID-19, and spirituality well-being $(N=280)$.

\begin{tabular}{lcc}
\hline Variables & Frequency & Percentage (\%) \\
\hline Self-report mental health status & 9 & 3.2 \\
Poor & 51 & 18.2 \\
Fair & 116 & 41.4 \\
Good & 71 & 25.4 \\
Very Good & 33 & 11.8 \\
Excellent & & \\
PHQ-4 & 168 & 60.0 \\
Good & 99 & 35.4 \\
Moderate & 13 & 4.6 \\
Poor & & \\
FCV-19S & 4 & 1.4 \\
Low & 270 & 96.4 \\
Moderate & 6 & 2.1 \\
High & 169 & 3.9 \\
SWBQ & 100 & 60.4 \\
Low & & 35.7 \\
Moderate & 11 & \\
High & & 3.9 \\
\hline
\end{tabular}

research hypotheses regarding the effect of spirituality between the fear of COVID-19 and mental health. For analysis tool, the SmartPLS 2.0 program was used. The PLS regression path model stands for a structural equation model. It is based on principal component, that is, total dispersion. This technique can evaluate measurement for validity of variable and structural model (Hair et al., 2016).

\section{Measurement Model Analysis}

In this study, to analyze measurement models, the confirmatory factor analysis (CFA) was conducted. The results are derived from 
TABLE 3 | Result of crossloading/loadings.

\begin{tabular}{|c|c|c|c|c|c|c|}
\hline & Fear & Mental health & Environmental & Transcendental & Personal & Communal \\
\hline $\mathrm{F} 1$ & 0.720 & & & & & \\
\hline F3 & 0.789 & & & & & \\
\hline F7 & 0.758 & & & & & \\
\hline $\mathrm{MH1}$ & & 0.807 & & & & \\
\hline $\mathrm{MH} 2$ & & 0.806 & & & & \\
\hline MH3 & & 0.821 & & & & \\
\hline $\mathrm{MH} 4$ & & 0.777 & & & & \\
\hline S11 & & & 0.942 & & & \\
\hline $\mathrm{S} 13$ & & & 0.948 & & & \\
\hline S15 & & & 0.919 & & & \\
\hline S17 & & & & 0.832 & & \\
\hline S18 & & & & 0.852 & & \\
\hline S19 & & & & 0.828 & & \\
\hline S2 & & & & & 0.886 & \\
\hline S5 & & & & & 0.754 & \\
\hline S6 & & & & & & 0.880 \\
\hline S10 & & & & & & 0.777 \\
\hline
\end{tabular}

analysis on the PLS measurement model. The convergent validity, internal consistency, and discriminant validity were analyzed the measurement model to evaluate and identify the suitability of them (Hair et al., 2016).

\section{Convergent Validity}

Convergent validity can be comprehended through individual measuring items for reliability purpose. For individual measuring items with reliability, the loading values should be 0.7 ideally, and 0.6 at minimum in Table 3 (Hair et al., 2016).

As shown in Table 1, all the individual measuring items' value is above 0.720 , in which all the items exceed 0.70 or above. Thus, all the measuring items used in this study are valid and indicate that all items secured convergent validity.

\section{Internal Consistency}

As internal consistency is a level of validity in which a latent variable set of specific observed variable reflects latent variable, Cronbach's alpha, average variance extracted (AVE), and composite reliability were used to analyze the internal consistency of measuring model. Generally, it has reliability if it is 0.6 or above in Cronbach's alpha and if it is 0.5 or above in AVE value, and it has internal consistency if it is 0.7 or above in composite reliability. As the internal consistency shown in Table 4, all the

TABLE 4 | Internal consistency.

\begin{tabular}{lccc}
\hline Constructs & $\begin{array}{c}\text { Composite } \\
\text { reliability }\end{array}$ & $\begin{array}{c}\text { Cronbach } \\
\text { alpha }\end{array}$ & $\begin{array}{c}\text { Average variance } \\
\text { extracted (AVE) }\end{array}$ \\
\hline Communal & 0.815 & 0.600 & 0.689 \\
Environmental & 0.955 & 0.930 & 0.877 \\
Fear & 0.800 & 0.626 & 0.572 \\
Mental Health & 0.879 & 0.819 & 0.645 \\
Personal & 0.807 & 0.600 & 0.677 \\
Transcendental & 0.875 & 0.787 & 0.701
\end{tabular}

items exceed the above-stated threshold, which secures internal consistency (Hair et al., 2017).

\section{Discriminant Validity}

The level of discriminating a concept of a specific latent variable from a concept of other latent variables is called discriminant validity. In this study, a variable has validity if it uses a square root value of mean dispersion extracted value of all the extracted variables, and an AVE square root value is higher compared with correlation coefficient. The AVE value should 0.70 or above (Hair et al., 2017).

The establishment of discriminant validity of the constructs was presented in Table 5. The threshold criteria at below 1 have achieved to all constructs (Henseler et al., 2016). Thus, it shows that each construct achieved the discriminant validity.

\section{Structural Model Analysis}

The structural model evaluates variance explanation power $\left(R^{2}\right)$ of structural concept and also evaluates significance of path coefficient $(\beta)$ expressing causal relationship information between two variables through structural equation analysis.

In Table 6, the finding that presented H1 strongly supports (standardized beta $=-0.761, p=0.00$ ) that the fear has significant effects on spirituality, and $\mathrm{H} 2$ was supported the spirituality significant effect on mental health (standardized beta $=-0.212$, $p=0.03)$.

Meanwhile, in $\mathrm{H} 3$, there was no significant association found between fear and mental health (standardized beta $=0.136$, $p=0.18$ ). The findings also show that the modeled constructs explain substantial variances in endogenous constructs with good predictive relevance. R2 values were found to be at substantial level for one endogenous construct: SPY $\left(R^{2}=57.9 \%\right)$; and two endogenous constructs: $\mathrm{MH}\left(R^{2}=10.7 \%\right)$. Figure 2 demonstrates the structural and measurement models of this study. 


\section{Mediation Effect of Spirituality Between Fear and Mental Health}

Table 7 presents the results of hypothesis testing for the indirect path. The findings in Table 7 concluded a significant indirect effect of spirituality on the relationship between fear and mental health $(\beta=0.161, t$-value $=2.156, p$-value $=0.03)$. The results confirmed that spirituality is a mediator that completely mediate the effects of fear on mental health, and thus it supports H4.

Coronavirus disease pandemic is impactful on people's life due to several reasons such as lockdowns (Meda et al., 2020) and associated isolation (Hwang et al., 2020), fear of worthlessness, and fear of infection (Dubey et al., 2020). Two of the critical antecedents of such mental health problems might include fear of COVID-19 and spirituality. Thus, this study aimed to investigate whether (a) fear of COVID-19 is related to spirituality, (b) spirituality is related to mental health, (c) fear of COIVD10 is related to mental health, and (d) whether spirituality mediates the relationship between fear of COVID-19 and mental health. In this regard, this study reports three main results: (a) fear of COVID-19 significantly impacts on spirituality, (b) spirituality significantly impacts on mental health, and c) spirituality mediates the relationship between fear of COVID-19 and mental health.

\section{Relationship Between Fear and Spirituality}

Concerning the first hypothesis, this study revealed that fear and spirituality had a significant relationship on mental health. Such results indicate that even if people are afraid of COVID19, the importance of faith will transcend this anxiety and it brings more positive vibration and compassion within themselves where it makes someone deal with their state of mental health. Such results support the findings of Polizzi et al. (2020), according to which many citizens were happy to uphold spirituality values in times of crisis. They agree that even such actions will offer them more positive values and contribute to better mental health.

\section{Significant Relationship Between Spirituality and Mental Health}

In accordance with the second hypothesis, the findings of the SMART PLS analysis conveyed that spirituality significantly effected on the mental health. This finding shows how important spirituality values are when looking into mental health among people, especially during the COVID-19 pandemic. In her writing, Rosmiran (2020) said that she spoke and encouraged her patients to always have faith and hope in overcoming their mental problems, especially during the COVID-19 pandemic. In this pandemic, many patients became worried about their futures, but hope and faith could make them more effectively transcend their state of mental health. This reveals how much faith ideals will improve more positive mental health, and this research shows how belief has more impact when it comes to mental health relative to anxiety.

\section{Relationship Between Fear and Mental Health}

Furthermore, the third hypothesis result found that fear of COVID-19 does not significantly effected on the mental health. People get worried quickly and are worried of diseases, especially during the COVID-19 pandemic. People are fearful easily because of the volume of social media information related to cases of people being hurt and dying every day. This condition is referred

TABLE 5 | Discriminant validity.

\begin{tabular}{|c|c|c|c|c|c|c|}
\hline & Communal & Environmental & Fear & Mental health & Personal & Transcendental \\
\hline Communal & 0.830 & & & & & \\
\hline Environmental & 0.774 & 0.936 & & & & \\
\hline Fear & -0.658 & -0.575 & 0.756 & & & \\
\hline Mental Health & -0.257 & -0.200 & 0.297 & 0.803 & & \\
\hline Personal & 0.762 & 0.797 & -0.744 & -0.319 & 0.823 & \\
\hline Transcendental & 0.469 & 0.448 & -0.605 & -0.327 & 0.542 & 0.837 \\
\hline
\end{tabular}

TABLE 6 | Result bootstrapping.

\begin{tabular}{|c|c|c|c|c|c|c|c|c|}
\hline Hypothesis & Path & Beta & S.D & $t$-value & $p$-values & Results & $f^{2}$ & $R^{2}$ \\
\hline $\mathrm{H} 1$ & $\mathrm{FR} \rightarrow \mathrm{SPY}$ & -0.761 & 0.033 & 23.070 & 0.00 & Supported & 1.373 & 0.579 \\
\hline $\mathrm{H} 2$ & $\mathrm{SPY} \rightarrow \mathrm{MH}$ & -0.212 & 0.099 & 2.139 & 0.03 & Supported & 0.021 & 0.107 \\
\hline $\mathrm{H} 3$ & $\mathrm{FR} \rightarrow \mathrm{MH}$ & 0.136 & 0.103 & 1.325 & 0.18 & Not Supported & 0.002 & \\
\hline
\end{tabular}

TABLE 7 | Mediation effect result.

\begin{tabular}{|c|c|c|c|c|c|c|}
\hline \multirow[t]{2}{*}{ Path } & \multirow[t]{2}{*}{ Hypothesis } & \multicolumn{4}{|c|}{ Indirect Effects } & \multirow[t]{2}{*}{ Results } \\
\hline & & Beta & Standard deviation & $t$-value & $p$-value & \\
\hline $\mathrm{FR} \rightarrow$ SPYmediated by MH & $\mathrm{H} 4$ & 0.161 & 0.075 & 2.156 & 0.03 & Supported \\
\hline
\end{tabular}




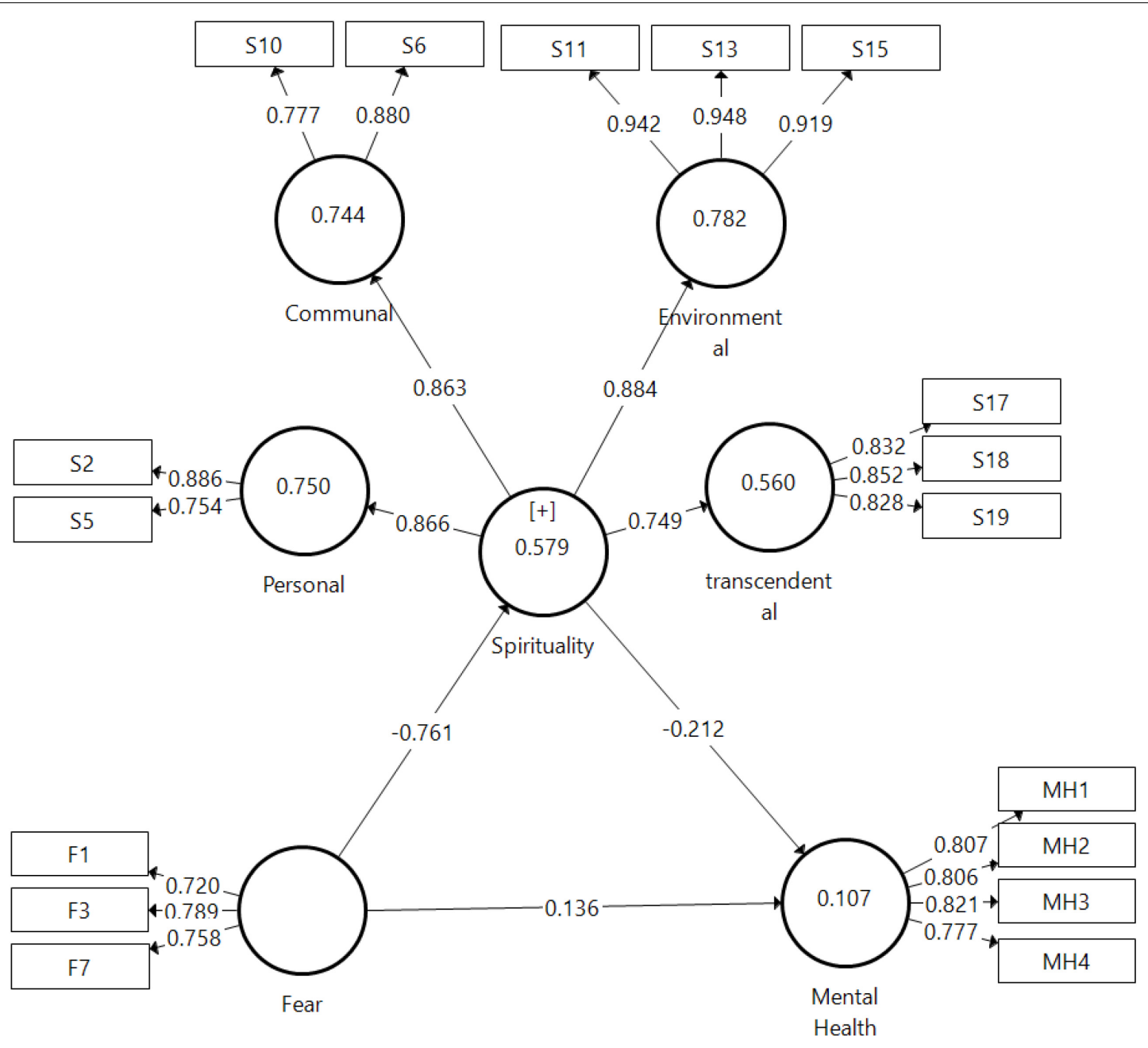

FIGURE 2 | Structural model analysis results. Obtained from Universiti Malaysia Sabah.

to as hypochondriatic anxiety disorder or health anxiety disorder. Fear and anxiety over well-being will trigger certain mental health problems, such as excessive stress and worries, and if ignored too, such doubts and suspicions can create many other mental health issues. But by spirituality, respondent's fear of COVID-19 was overcome and their mental health reduced. It is the evidence based on this study, which clearly does not impact the skepticism of COVID-19 on mental health. COVID-19's mistrust of faith impacts on mental health. It illustrates how spirituality values can help people deal with anxiety and mental health problems. Adults also need a lot of exposes to COVID-19 pandemic and how they can protect themselves (Rathakrishnan and Alfred, 2013). Adults who staying in rural area more are affected by their psycho well-being and mental health especially on COVID-19 pandemic (Rathakrishnan et al., 2019).

Finally, the fourth hypothesis found spirituality significantly mediated the relationship between fear of COVID-19 and mental health. This study affirms the importance of spirituality as a factor between fear and mental health. When spirituality values are high, people give less importance to emotion and become more focused on daily work. Even if people are experiencing social distancing and also having less social connectedness with their friends, family members, and colleagues, with spiritually, they can have faith and hope. This spirituality reduces their fear of disease. The result further shows that spirituality values could help people with fear to manage their mental health better. Spirituality makes them stronger in their relationship with fear and mental health. This result helps add to the overgrowing call for the mental health professional and counselor in hospital, school, and university. Fear of the disease can be reduced if spirituality wellbeing is imposed to increase positive mental health, especially throughout the COVID-19 pandemic. That means counselors and mental health professionals need to integrate spirituality well-being with fear and mental health. This spirituality values help adults to overcome fear, and it will increase positive mental health. Furthermore, this finding supports that counselor should consider spirituality values to reduce the number of people who have mental health and fear of COVID-19. An intervention to help adults who are having fear and mental health issue should focus on spirituality (Beckstein et al., 2021). This will help adults 
to increase their belief and positive values to control their fear and mental health issues (Liu et al., 2020, Rathakrishnan and George, 2021). Another essential point is that counselors and mental health professionals need to understand the role of spirituality in the life of the client (Seybold and Hill, 2001; Miller and Thoresen, 2003; Koenig, 2010). Counselors need to understand how to integrate their client's spirituality values in their intervention and to help clients who have a fear of the COVID-19 and mental health issue. The process of intervention should focus on spirituality and values of positive well-being (Seligman, 2002).

\section{Limitation}

Justification in terms of location, time, or respondents' characteristics also needs to be taken care. This study has the characteristics of a pilot study due to the limited sample size of adults. There should be more data collected.

\section{Improvement}

In future, research also can focus on more respondents and gives important of value of spirituality on the mental health and what type of invention using spirituality could ease the mental health among adults. Thus, it could be interesting in future occasions to assess the use of measures on other aspects of spirituality or religiosity (closeness to God, religious support.) and even introduce qualitative methodology.

\section{CONCLUSION}

In conclusion, this study has identified the mediating role of spirituality in the relationship between fear of COVID-19 and mental health. The result demonstrated that there is a link between fear of COVID-19 and spirituality toward mental health. For future research, there is a need to conduct more research related to spirituality, fear, and mental health among people who are going through a COVID-19 pandemic. Fear of COVID-19 is

\section{REFERENCES}

Ahorsu, D. K., Lin, C. Y., Imani, V., Saffari, M., Griffiths, M. D., and Pakpour, A. H. (2020). The fear of COVID-19 scale: development and initial validation. Int. J. Ment. Health Addict. [Epub ahead of print]. doi: 10.1007/s11469-020-0 0270-8

Barkur, G., and Vibha, G. B. K. (2020). Sentiment analysis of nationwide lockdown due to COVID 19 outbreak: evidence from India. Asian J. Psychiatr. 51:102089. doi: 10.1016/j.ajp.2020.102089

Beckstein, A., Rathakrishnan, B., Hutchings, P. B., and Hassline Mohamed, N. (2021). The covid-19 pandemic and mental health in malaysia: current treatment and future recommendations. Malays. J. Public Health Med. 21, 260-267. doi: 10.37268/mjphm/vol.21/no.1/art.826

Bonelli, R., Dew, R. E., Koenig, H. G., Rosmarin, D. H., and Vasegh, S. (2012). Religious and spiritual factors in depression: review and integration of the research. Depress. Res. Treat. 2012:962860. doi: 10.1155/2012/962860

Brown, D. R., Carney, J. S., Parrish, M. S., and Klem, J. L. (2013). Assessing spirituality: the relationship between spirituality and mental health. J. Spiritual. Ment. Health 15, 107-122.

de Hoog, N., Stroebe, W., and de Wit, J. B. (2008). The processing of fear-arousing communications: how biased processing leads to persuasion. Soc. Influ. 3, 84-113. an issue that needs to be explored to understand further about how it affects mental health among adults in Malaysia. Because people cannot be connected, it makes them more stressful and fearful of this disease. With more research and findings, there could be more counselors and mental health professionals who are culturally based and can tackle more issues related to mental health during times of a pandemic. This will help more counselors and mental professionals become well-equipped with more specific intervention methods for a pandemic.

\section{DATA AVAILABILITY STATEMENT}

The raw data supporting the conclusions of this article will be made available by the authors, without undue reservation.

\section{ETHICS STATEMENT}

The studies involving human participants were reviewed and approved by Universiti Malaysia Sabah [JKEtika 3/20 (11)]. The patients/participants provided their written informed consent to participate in this study.

\section{AUTHOR CONTRIBUTIONS}

All authors listed have made a substantial, direct, and intellectual contribution to the work, and approved it for publication.

\section{FUNDING}

This study is funded under grant from University Malaysia Sabah (SDK 0194-2020).

Druss, B. G. (2020). Addressing the COVID-19 Pandemic in Populations with Serious Mental Illness. JAMA Psychiatry 77, 891-892. doi: 10.1001/ jamapsychiatry.2020.0894

Dubey, S., Biswas, P., Ghosh, R., Chatterjee, S., Dubey, M. J., Chatterjee, S., et al. (2020). Psychosocial impact of COVID-19. Diabetes Metab. Syndr. 14, 779-788. doi: 10.1016/j.dsx.2020.05.035

Fardin, M. A. (2020). COVID-19 Epidemic and spirituality: a review of the benefits of religion in times of crises. J. Chronic Dis. Care 9, 10-14.

Gomez, R., and Fisher, J. W. (2003). Domains of spiritual well-being and development and validation of the Spiritual Well-Being Questionnaire. Pers. Individ. Dif. 35, 1975-1991.

Graham, S., Furr, S., Flowers, C., and Burke, M. T. (2001). Research and theory religion and spirituality in coping with stress. Couns. Values 46, 2-13.

Hair, J. F., Hollingsworth, C. L., Randolph, A. B., and Chong, A. Y. L. (2017). An updated and expanded assessment of PLS-SEM in information systems research. Ind. Manag. Data Syst. 117, 442-458.

Hair, J. F., Hult, G. T. M., Ringle, C., and Sarstedt, M. (2016). A Primer on Partial Least Squares Structural Equation Modeling (PLS-SEM), 2nd Edn. Thousand Oaks, CA, USA: Sage.

Halliwell, E. (2009). In The Face Of Fear: how Fear And Anxiety Affect Our Health And Society, And What We Can Do About It. London: Mental Health Foundation. 
Hayman, J. W., Kurpius, S. R., Befort, C., Nicpon, M. F., Hull-Blanks, E., Sollenberger, S., et al. (2007). Spirituality among college freshmen: relationships to self-esteem, body image, and stress. Couns. Values 52, 55-70.

Henseler, J., Hubona, G., and Ray, P. A. (2016). Using PLS path modeling in new technology research: updated guidelines. Ind. Manag. Data Syst. 116, $2-20$.

Holmes, E. A., O’Connor, R. C., Perry, V. H., Tracey, I., Wessely, S., Arseneault, L., et al. (2020). Multidisciplinary research priorities for the COVID-19 pandemic: a call for action for mental health science. Lancet Psychiatry 7, 547-560. doi: 10.1016/S2215-0366(20)30168-1

Holt-Lunstad, J., Smith, T. B., Baker, M., Harris, T., and Stephenson, D. (2015). Loneliness and Social Isolation as Risk Factors for Mortality: a metaanalytic review. Perspect. Psychol. Sci. 10, 227-237. doi: 10.1177/174569161456 8352

Hwang, T. J., Rabheru, K., Peisah, C., Reichman, W., and Ikeda, M. (2020). Loneliness and Social Isolation during the COVID-19 Pandemic. Int. Psychogeriatr. 32, 1217-1220.

Koenig, H. G. (2010). Spirituality and mental health. Int. J. Appl. Psychoanal. Stud. 7, 116-122. doi: 10.1002/aps.239

Kroenke, K., Spitzer, R. L., Williams, J. B., and Löwe, B. (2009). An ultra-brief screening scale for anxiety and depression: the PHQ-4. Psychosomatics 50, 613-621. doi: 10.1176/appi.psy.50.6.613

Laurance, J. (2003). Pure Madness: how Fear Drives The Mental Health System. London and New York: Routledge.

Levin, J. S. (2009). How faith heals: a theoretical model. Explore 5, 77-96. doi: 10.1016/j.explore.2008.12.003

Li, W., Yang, Y., Liu, Z. H., Zhao, Y. J., Zhang, Q., Zhang, L., et al. (2020). Progression of mental health services during the COVID-19 outbreak in China. Int. J. Biol. Sci. 16, 1732-1738. doi: 10.7150/ijbs.45120

Liu, S., Yang, L., Zhang, C., Xiang, Y. T., Liu, Z., Hu, S., et al. (2020). Online mental health services in China during the COVID-19 outbreak. Lancet Psychiatry 7, e17-e18. doi: 10.1016/S2215-0366(20)30077-8

Meda, N., Pardini, S., Slongo, I., Bodini, L., Rigobello, P., Visioli, F., et al. (2020). COVID-19 and depressive symptoms in students before and during lockdown. medRxiv [preprint]. doi: 10.1101/2020.04.27.20081695

Miller, W. R., and Thoresen, C. E. (2003). Spirituality, religion, and health: an emerging research field. Am. Psychol. 58, 24-35. doi: 10.1037/0003-066x. 58.1.24

Mohd Majid, K. (2002). Kaedah Penyelidikan Pendidikan. Edisi ke-3. Kuala Lumpur: Dewan Bahasa dan Pustaka.

Montemurro, N. (2020). The emotional impact of COVID-19: from medical staff to common people. Brain Behav. Immun. 87, 23-24. doi: 10.1016/j.bbi.2020. 03.032

Pargament, K. I., Kennell, J., Hathaway, W., Grevengoed, N., Newman, J., and Jones, W. (1988). Religion and problem-solving process: three styles of coping. J. Sci. Study Relig. 27, 90-104.

Polizzi, C., Lynn, S. J., and Perry, A. (2020). Stress and coping in the time of COVID-19: pathways to resilience and recovery. Clin. Neuropsychiatry 17, 59-62. doi: 10.36131/CN20200204

Powell, L. H., Shahabi, L., and Thoresen, C. E. (2003). Religion and spirituality: linkages to physical health. Am. Psychol. 58, 36-52. doi: 10.1037/0003066x.58.1.36

Rathakrishnan, B., and Alfred, C. (2013). Stress and Mental Problem secondary school student in Sabah, Malaysian. J. Youth Stud. 8, 167-176. doi: 10.1186/ s12889-021-10440-5

Rathakrishnan, B., Bikar Singh, S. S., Kamaluddin, M. R., Ghazali, M. F., Yahaya, A., Mohamed, N. H., et al. (2021). Homesickness and Socio-Cultural Adaptation towards Perceived Stress among International Students of a Public University in Sabah: an Exploration Study for Social Sustainability. Sustainability 13:4924. doi: 10.3390/su13094924

Rathakrishnan, B., and George, S. (2021). Gambling in Malaysia: an overview. BJPsych Int. 18, 32-34. doi: 10.1192/bji.2020.55

Rathakrishnan, B., Sanu, M. E., Yahaya, A., Bikar Singh, S. S., and Kamaluddin, M. R. (2019). Emotional intelligence and psychological well-being of rural poor school students in Sabah, Malaysia. Psympathic: Jurnal Ilmiah Psikologi 6, 65-72. doi: 10.14331/ijfpss.2015.330048
Reutter, K. K., and Bigatti, S. M. (2014). Religiosity and spirituality as resiliency resources: moderation, mediation, or moderated mediation? J. Sci. Study Relig. 53, 56-72.

Richards, P. S., and Bergin, A. E. (2005). A spiritual strategy for counseling and psychotherapy, 2nd Edn. Washington, DC: American Psychological Association.

Rosmiran (2020). Making Connections: spirituality, Mental Health, and COVID19. Available Online at: https://www.mcleanhospital.org/news/makingconnections-spirituality-mental-health-and-covid-19 (accessed August 11, 2020).

Roy, D., Tripathy, S., Kar, S. K., Sharma, N., Verma, S. K., and Kaushal, V. (2020). Study of knowledge, attitude, anxiety \& perceived mental healthcare need in Indian population during COVID-19 pandemic. Asian J. Psychiatr. 51:102083.

Sekaran, U., and Bougie, R. (2013). Research Methods for Business: a Skill-Building Approach. New York: Wiley.

Seligman, M. E. (2002). "Positive psychology, positive prevention, and positive therapy," in Handbook of positive psychology, eds C. R. Snyder and S. J. Lopez (Oxford: Oxford University Press), 3-12.

Seybold, K. S., and Hill, P. C. (2001). The role of religion and spirituality in mental and physical health. Curr. Dir. Psychol. Sci. 10, 21-24.

Srinivasan, J., Cohen, N. L., and Parikh, S. V. (2003). Patient attitudes regarding causes of depression: implications for psychoeducation. Can. J. Psychiatry 48, 493-495. doi: 10.1177/070674370304800711

Thune-Boyle, I. C., Stygall, J. A., Keshtgar, M. R., and Newman, S. P. (2006). Do religious/spiritual coping strategies affect illness adjustment in patients with cancer? A systematic review of the literature. Soc. Sci. Med. 63, 151-164. doi: 10.1016/j.socscimed.2005.11.055

Thurston, N. S. (1999). "Religious Problem-Solving Scale [Review of the Religious Problem- Solving Scale]," in Measures of Religiosity, eds P. C. Hill and R. W. Hood Jr. (Birmingham, AL: Religious Education Press), 347-350.

Trigwell, J. L., Francis, A. J., and Bagot, K. L. (2014). Nature connectedness and eudaimonic well-being: spirituality as a potential mediator. Ecopsychology 6, 241-251.

Westgate, C. E. (1996). Spiritual wellness and depression. J. Couns. Dev. 75, 26-35. WHO (2020). WHO Director-General's opening remarks at the media briefing on COVID-19 -11 March 2020. Available online at: https://www.who.int/director-general/speeches/detail/who-director-generals-opening-remarks-at-the-media-briefing-on-covid-19-11-march-2020 (accessed August 15, 2020).

Xiang, Y. T., Yang, Y., Li, W., Zhang, L., Zhang, Q., Cheung, T., et al. (2020). Timely mental health care for the 2019 novel coronavirus outbreak is urgently needed. Lancet Psychiatry 7, 228-229. doi: 10.1016/S2215-0366(20)30046-8

Young, J. S., Wiggins-Frame, M., and Cashwell, C. S. (2007). Spirituality and counselor competence: a national survey of American Counseling Association members. J. Couns. Dev. 85, 47-52.

Zhang, S. X., Huang, H., and Wei, F. (2020). Geographical distance to the epicenter of Covid-19 predicts the burnout of the working population: ripple effect or typhoon eye effect? Psychiatry Res. doi: 10.1016/j.psychres.2020.112998 288:112998.

Conflict of Interest: The authors declare that the research was conducted in the absence of any commercial or financial relationships that could be construed as a potential conflict of interest.

Publisher's Note: All claims expressed in this article are solely those of the authors and do not necessarily represent those of their affiliated organizations, or those of the publisher, the editors and the reviewers. Any product that may be evaluated in this article, or claim that may be made by its manufacturer, is not guaranteed or endorsed by the publisher.

Copyright (c) 2022 Rathakrishnan, Singh, Yahaya, Kamaluddin and Aziz. This is an open-access article distributed under the terms of the Creative Commons Attribution License (CC BY). The use, distribution or reproduction in other forums is permitted, provided the original author(s) and the copyright owner(s) are credited and that the original publication in this journal is cited, in accordance with accepted academic practice. No use, distribution or reproduction is permitted which does not comply with these terms. 